(c) American Dairy Science Association, 2006.

\title{
Brisket Boards Reduce Freestall Use
}

\author{
C. B. Tucker, ${ }^{1}$ G. Zdanowicz, and D. M. Weary \\ Animal Welfare Program, University of British Columbia, Vancouver, Canada V6T 1 Z4
}

\begin{abstract}
We examined how the presence of a brisket board influenced cow preference, stall use, and position within the stall. When given a choice between stalls with or without a brisket board, 15 nonlactating cows spent $68 \%$ of their time lying in the stalls without a brisket board, indicating that they preferred this option. When 13 cows had access to either stalls with a brisket board or ones without, they spent, on average, $1.2 \mathrm{~h} / \mathrm{d}$ more time lying down in stalls without a brisket board. Resting cows positioned themselves relatively forward in the stalls in $98 \pm 5 \%$ (mean \pm SE) of lying bouts when the brisket board was absent, compared with $67 \pm 5 \%$ of bouts when the board was present. Longer cows were more likely than shorter cows to move forward in the stalls without a brisket board. Cows also had longer lying bouts in stalls without the brisket board (absent: $1.7 \pm 0.08$; present: $1.5 \pm 0.08 \mathrm{~h} / \mathrm{bout}$ ). Although it seems likely that the brisket board helps keep stalls clean by positioning cows closer to the curb, our results indicate that brisket boards also make stalls less comfortable for cows. Stall features designed to reduce stall maintenance may compromise cow comfort. We suggest that new approaches to cow housing are now required.

Key words: cubicle, housing, welfare, behavior
\end{abstract}

\section{INTRODUCTION}

Modern housing for farm animals frequently includes features designed to improve convenience for the animal caretaker by modifying animal behavior. For dairy cattle, features of the freestall are designed to limit where the cow stands and lies to reduce the labor required to keep the stalls clean. For example, neck rails help keep stalls clean by preventing cows from standing with all four hooves in the stall (Tucker et al., 2005). Similarly, electric cow trainers encourage standing cows to step backward into the alley when defecating or urinating (Bergsten and Pettersson, 1992). Although neck rails and electric cow trainers aim to manipulate

Received October 3, 2005.

Accepted January 13, 2006.

${ }^{1}$ Corresponding author: cassandra.tucker@agresearch.co.nz defecation and urination while standing, these features address only part of the problem, because $69 \%$ of defecations soiling the freestall occur while cows are lying down when the neck rail is present (Tucker et al., 2005). A barrier at the front of the freestall, the brisket board, is designed to control the position of the recumbent cow and thus decrease the chances for defecation in the stall while lying down.

Improving cow housing requires that we assess the efficacy of such stall features in achieving the perceived benefits (such as improved stall cleanliness) while ensuring that the design has little or no negative impact on cow comfort. Only one study has examined the effect of brisket boards on cow behavior; this research (Veissier et al., 2004) indicated that brisket boards reduce lying time, but the effect of treatment was confounded with time, making it difficult to draw firm conclusions.

Thus, the aim of the current experiment was to test the effect of the brisket board on measures of dairy cow comfort, specifically on their stall preference and stall usage. We also assessed how the brisket board affects the lying position in the stall, because this is thought to affect stall cleanliness. We predicted that cows would prefer stalls without a brisket board, use these stalls more, and that they would position themselves further from the curb when lying in stalls without a brisket board.

\section{MATERIALS AND METHODS}

Fifteen nonlactating, pregnant Holstein cows were studied between June and September 2003 at the University of British Columbia (UBC) South Campus Research and Teaching Complex in Vancouver. Cows averaged (mean \pm SD) $2 \pm 1$ lactations, weighed $702 \pm 70$ $\mathrm{kg}$, and measured $142 \pm 4 \mathrm{~cm}$ high at the third thoracic vertebra (cow height) and $129 \pm 6 \mathrm{~cm}$ between the third vertebra and the most caudal vertebra at the base of the tail (cow length). All cows had been housed previously in freestalls with 10-cm-high brisket boards (Poly Pillow, Promat Ltd., Seaforth, Ontario, Canada) placed $227 \mathrm{~cm}$ from the rear end of the stall. Each cow was housed individually in a test pen with access to a feed trough, a waterer, and 2 freestalls that were accessible from an alley. All flooring outside the freestall area was concrete. 
Stalls were fitted with a rubber-filled geotextile mattress (Pasture Mat, Promat Ltd.) and bedded with 3 to $5 \mathrm{~cm}$ of sawdust. The stalls measured $121 \mathrm{~cm}$ wide and $272 \mathrm{~cm}$ long, with a 125-cm-high neck rail placed 160 $\mathrm{cm}$ from the rear end of the stall. These stall dimensions are similar to configurations used in our previous work (Tucker et al., 2004, 2005). Feces were removed and the bedding was leveled each day (with sawdust bedding added if necessary) during the morning and afternoon feedings (0800 and $1500 \mathrm{~h}$ ). Cows were fed alfalfa hay ad libitum.

Trios of cows were tested simultaneously in 3 identical test pens in a barn, as described by Tucker et al. (2003). Design of the stall partitions was described previously by Tucker et al. (2004). In each test pen, one of the stalls was equipped with a wooden brisket board (20 $\mathrm{cm}$ high, $227 \mathrm{~cm}$ from the rear end of the stall, at a $30^{\circ}$ angle relative to the stall surface) and the other stall did not contain a brisket board. The location of the 2 treatments within the pen was switched after each trio of cows and balanced across the experiment.

Each test consisted of 3 phases. During the first, or adjustment, phase, cows had free access to both stalls for $7 \mathrm{~d}$. During the second, or restriction, phase, cows were allowed access to only a single stall at a time by blocking access to the other stall, each for a 4-d period. The order of access for each cow was assigned randomly, without replacement, and balanced across the experiment. During the final, or free-choice, phase, cows were again allowed access to both stalls for $3 \mathrm{~d}$.

The behavior of the cows was video recorded during all $4 \mathrm{~d}$ for both treatments during the restriction phase and during the 3-d free-choice phase, for a total of 11 $\mathrm{d}$ of recording for each cow. Each pen was recorded at 3 frames/s using time-lapse video equipment (Tucker et al., 2005). These recordings were reviewed continuously and the following behaviors were measured: 1) time spent lying in the stall, 2) time spent standing with at least 2 hooves in the stall, 3) number of lying bouts, and 4) number of times the cow entered the stall with at least the front hooves in the stall (visits to the stall). In addition, the position of the cow was recorded $1 \mathrm{~min}$ after the start of each lying bout and $1 \mathrm{~min}$ before the end of each lying bout. This was done by noting whether the third vertebra (which was marked with reflective tape) was located on the curb side of the neck rail, under the neck rail, or in front of the neck rail. The mean lying-bout duration was calculated for each cow in each 24-h period by dividing the total lying time by the number of lying bouts. Lying behavior outside the stall was not recorded. Video data were lost for 2 cows during the restriction phase, and the height measurement from 1 cow was not obtained.

\section{Statistical Analyses}

Information from the restriction phase was used to determine how the presence of a brisket board affected the cows' stall use and their position within the freestall. Data were averaged across the 4-d collection period for each treatment. Residual plots of many measures were not uniform and transformations could not correct this problem, so all behavioral data were converted to ranks using PROC RANK (SAS Institute, 1999) before analyses (Conover and Iman, 1981). We used a GLM procedure (SAS Institute, 1999) to test the effect of the presence of a brisket board and the interaction between this effect and cow size. Dependent variables were time spent lying and time standing in the stall, number of lying bouts, length of lying bouts, number of visits to the stall, and position at the start and end of each lying bout. Measures of cow size were weight, height, and length. The model statement included a term for a single measure of cow size ( $1 \mathrm{df}$ ), cow (11 df), order of exposure to each treatment ( $1 \mathrm{df})$, presence of a brisket board (treatment; $1 \mathrm{df}$ ) and a term for the interaction of treatment $\times$ cow size $(1 \mathrm{df})$. Treatment and interaction terms were tested by using the residual error from the model described above (10 df).

In the preference phase of the experiment, data were averaged across the 3-d collection period and analyzed using Wilcoxon signed-rank tests to compare 1) the percentage of time lying, 2) the percentage of time standing, and 3) the number of visits to the stall against the expected 50\%. Preference for treatment was based on the percentage of time spent lying, the percentage of time spent standing, and the number of visits to the stall. The interaction between the degree of preference and cow height and length was tested with Pearson correlations.

\section{RESULTS}

During the restriction phase, cows spent, on average, $1.2 \mathrm{~h} / \mathrm{d}$ more time $(P<0.01)$ lying down in stalls without a brisket board (Table 1). Longer lying times in these stalls were because of longer $(P<0.01)$ lying bouts, whereas the number of bouts did not differ between treatments. Cows were more likely $(P<0.01)$ to lie closer to the front of the stall when the brisket board was absent at both the start and end of lying bouts. Cows also spent $22 \mathrm{~min} / \mathrm{d}$ less time $(P<0.01)$ standing in stalls without a brisket board, although the number of visits to the stall did not differ between treatments.

The effect of brisket boards was mediated by cow length (Figure 1). When using the stalls without a brisket board, longer cows positioned themselves closer $(P$ $<0.05)$ to the front of the stall than shorter cows. No 
Table 1. Characteristics of stall use and positions within stalls with and without a brisket board ${ }^{1}$

\begin{tabular}{|c|c|c|c|c|c|c|}
\hline \multirow[b]{3}{*}{ Behavior } & \multirow{2}{*}{\multicolumn{2}{|c|}{ Brisket board }} & \multirow[b]{3}{*}{ SE } & \multicolumn{3}{|c|}{$P$-values } \\
\hline & & & & \multirow{2}{*}{$\begin{array}{l}\text { Treatment } \\
\text { (T) }\end{array}$} & \multirow{2}{*}{$\begin{array}{l}\mathrm{T} \times \text { cow } \\
\text { length }\end{array}$} & \multirow{2}{*}{$\begin{array}{l}\mathrm{T} \times \text { cow } \\
\text { height }\end{array}$} \\
\hline & Absent & Present & & & & \\
\hline Number of lying bouts, no./24 h & 8.3 & 8.7 & 0.29 & 0.400 & 0.005 & 0.296 \\
\hline Length of lying bout, h/bout & 1.7 & 1.5 & 0.08 & 0.001 & 0.001 & 0.885 \\
\hline Standing time, $\min / 24 \mathrm{~h}$ & 97 & 119 & 9.7 & 0.005 & 0.930 & 0.193 \\
\hline Number of visits to free stall, no./24 h & 6.7 & 7.2 & 0.39 & 0.217 & 0.690 & 0.530 \\
\hline
\end{tabular}

${ }^{1}$ Measures are from the restriction phase of the experiment $(\mathrm{n}=13)$. The $P$-values are based on a GLM with ranked values, and show the effects of treatment (i.e., brisket board present or absent) and the interaction between treatment and cow size (length and height).

${ }^{2}$ Measured by the position of the third vertebra on the curb side of the neck rail.

significant interaction was detected between cow height and treatment for any of the dependent variables.

During the free-choice phase, cows preferred to lie down in, and were more likely to enter $\left(P_{\text {signed-rank test }} \leq\right.$ 0.05 ), stalls without the brisket board (Table 2). Cows also tended to spend more time standing in these stalls $\left(P_{\text {signed-rank test }} \leq 0.09\right)$. Neither cow length nor cow height accounted for the variation in either measure of preference $\left(\mathrm{r}_{\text {Pearson }} \leq 0.32, P \geq 0.25\right)$.

\section{DISCUSSION}

Cows preferred entering and lying down in stalls without brisket boards. They did not show a preference for standing based on the presence or absence of a brisket board. These results are similar to the preferences shown for lying surfaces (Lowe et al., 2001; Manninen et al., 2002; Tucker et al., 2003; Tucker and Weary, 2004). The magnitude of the preference, an average of $68 \%$ of lying time in the preferred stall, was smaller than for preferred bedding materials (often $100 \%$ of the time lying on a single surface) and was similar to the magnitude of preference shown for flooring surfaces outside the stall (Stefanowska et al., 2002). By demonstrating a preference for stalls without brisket boards, the cows showed that they were able to make choices based on structures within the stall. This result differs from our previous work in which cows did not show clear preferences for stalls depending on the placement of overhead (i.e., neck-rail) or horizontal (stall-partition) structures (Tucker et al., 2004, 2005), and it supports the idea that cattle assess the entire lying surface (including other barriers), not just the conditions directly underfoot.

The brisket board also influenced the use of the stall when the cows had only one option. Lying times were, on average, $1.2 \mathrm{~h} / \mathrm{d}$ shorter when the stall contained a brisket board. The magnitude of this effect was similar to that of other experiments comparing the amount or depth of bedding (Tucker and Weary, 2004; Drissler et al., 2005) or stall width (Tucker et al., 2004). Indeed, across the 5 experiments, the average change in lying times in response to treatment was $1.5 \mathrm{~h} / \mathrm{d}$. The magnitude of this change in lying time differed from the effect of lying surface type, which, when significantly different, had a much larger effect on lying time than did the brisket board. In 8 experiments (Munksgaard et al., 1999; Haley et al., 2000, 2001; Manninen et al., 2002; Fisher et al., 2003; Tucker et al., 2003) in which significant differences in lying time were associated with the type of lying surface, the average difference in lying time was more than $4 \mathrm{~h} / \mathrm{d}$. Also, in the experiments on lying surface, very short lying times (0 to 6 $\mathrm{h} / 24 \mathrm{~h}$ ) were reported-values well outside the range considered normal for dairy cattle (Manninen et al., 2002; Fisher et al., 2003; Tucker et al., 2003). Taken together, these results indicate that stall features such as the brisket board influence stall use, but not to the same extent as the lying surface.

Shorter lying times in stalls with a brisket board were mainly because of a decrease in the average length of lying bouts. Previously, we speculated that shorter lying bouts were associated with contact with stall features, and the current results are consistent with this idea. We propose that cows' contact with stall features, while recumbent causes discomfort and consequently reduces the duration of lying bouts. Previously, we found that cows had shorter lying bouts when they were more likely to contact exposed concrete at the front or rear of the stall (Drissler et al., 2005), and when they were housed in narrow freestalls, where they were more likely to contact the stall partitions (Tucker et al., 2004).

We had expected that the removal of the brisket board would especially benefit larger cows. This prediction was supported in terms of the lying position. For example, longer cows were able to move farther forward in the stalls when the brisket board was absent, indicating that in the stalls having brisket boards, larger cows 
- Brisket board present o No brisket board
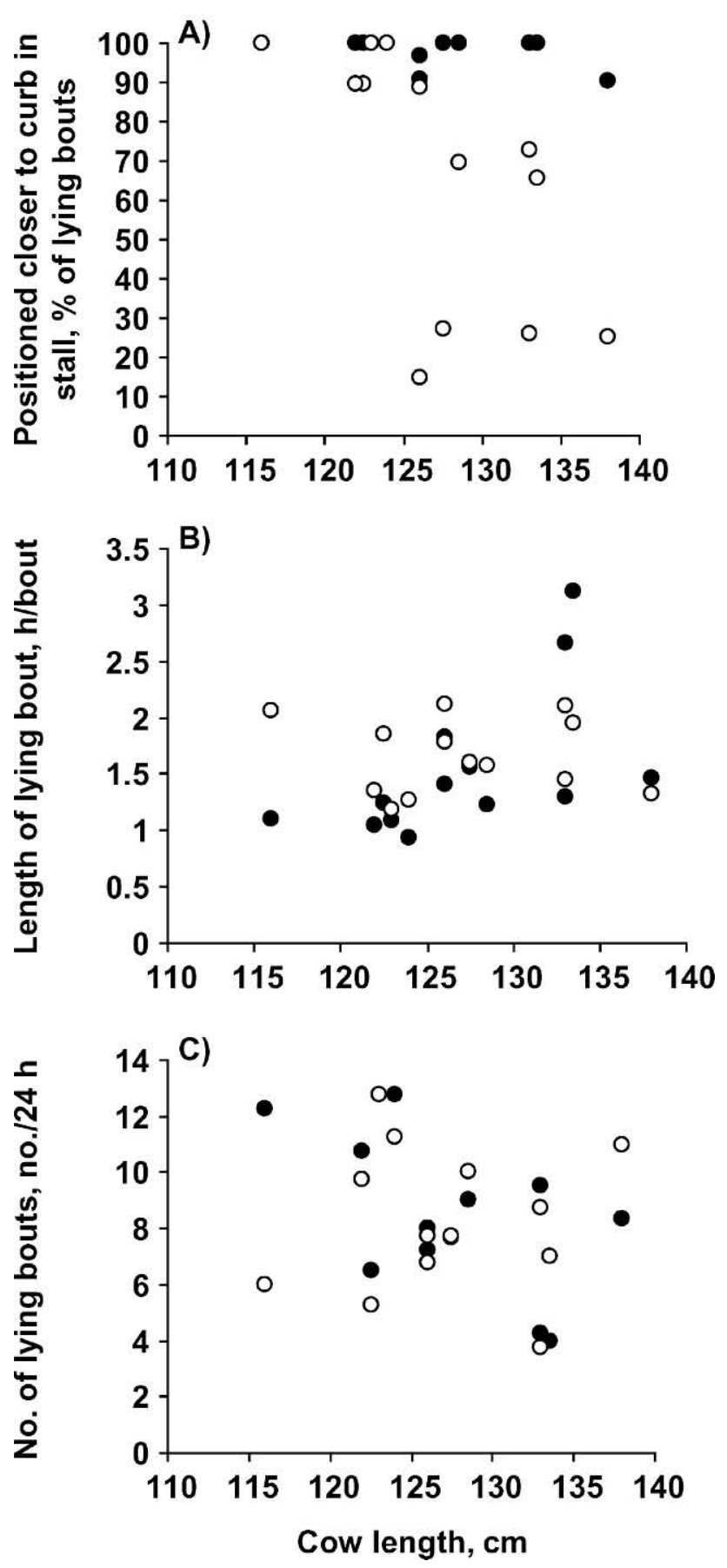

Figure 1. Effect of cow length on: A) lying position at the end of lying bouts, B) length of lying bouts, and C) number of lying bouts, shown separately for stalls with a brisket board present (solid circles) and stalls with no brisket board (open circles). Longer cows were more likely to lie forward in the stall when the brisket board was removed (interaction of treatment $\times$ cow length; $P=0.027$ ). Lying position in the stall was measured by the percentage of lying bouts when the position of the third thoracic vertebra was on the curb side of the neck rail.
Table 2. Results of the free-choice phase of the experiment: percentages of lying time, percentages of standing time, and visits to the stall without a brisket board ${ }^{1}$

\begin{tabular}{lccc}
\hline & \multicolumn{3}{c}{ Behavior performed in the stall, \% } \\
\cline { 2 - 4 } Cow & $\begin{array}{l}\text { Lying } \\
\text { time }\end{array}$ & $\begin{array}{c}\text { Standing } \\
\text { time }\end{array}$ & Visits \\
\hline 1 & 90 & 76 & 77 \\
2 & 63 & 57 & 53 \\
3 & 49 & 27 & 36 \\
4 & 40 & 55 & 58 \\
5 & 100 & 98 & 95 \\
6 & 94 & 75 & 88 \\
7 & 53 & 62 & 63 \\
8 & 59 & 33 & 41 \\
9 & 100 & 98 & 93 \\
10 & 9 & 9 & 17 \\
11 & 100 & 93 & 90 \\
12 & 100 & 100 & 100 \\
13 & 0 & 8 & 32 \\
14 & 97 & 93 & 95 \\
15 & 62 & 59 & 35 \\
Mean \pm SE & $68 \pm 8.7^{*}$ & $63 \pm 8.2$ & $65 \pm 7.3^{*}$ \\
\hline
\end{tabular}

${ }^{1}$ Average values for the 3 -d period are presented separately for each of the 15 individual cows.

*Signed rank test $(P \leq 0.05)$.

lacked adequate space to lie down comfortably. The graphical representation of the interaction between cow size and brisket board was much less clear for the frequency and duration of lying bouts, indicating that all cows may have benefited from the removal of the brisket board in terms of stall use.

We caution that our results are specific to the testing conditions of our experiment. As in all experimental research, addition replication over a range of conditions (e.g., bedding surfaces and freestall configurations) would help us understand the extent to which these results can be generalized. Interactions between placement of the neck rail and the brisket board may be of particular importance for cow comfort because neck rails likely influence the position of the cow before lying down. The neck-rail placement used this experiment may have affected lying position, even when the brisket board was absent. Indeed, the effect of the brisket board may be more pronounced when the neck-rail placement is less restrictive. It is also possible that other brisket board designs, such as those that are rounded, lower, or softer, may be less disturbing to cows than the wooden boards we tested. Finally, our experiment was carried out with pregnant, nonlactating cows. Future work, especially experiments that evaluate the effects of brisket boards on stall cleanliness, is needed to understand how lactating dairy cattle respond to this stall feature.

Previous work with lactating cattle also reported that cows lie farther forward in stalls without a brisket board (Veissier et al., 2004). Most of the defecations that soil the stall occur while cows are lying down (Tucker et 
al., 2005), so structures that keep them closer to the curb while recumbent would likely reduce stall maintenance. As with other labor-saving technology used for maintaining clean stalls, this increased efficiency likely comes at the cost of reduced cow comfort. In previous work we found that narrow stalls and ones with restrictive neck-rail placement were cleaner. However, it is important to note that these stalls were used less often, and this decreased usage itself reduced chances of stall soiling (Gaworski et al., 2003; Tucker et al., 2004, 2005). In combination with other work, these results indicate that most structures added to the stall (partitions, neck rail, brisket board, or curb at the end of the stall) make the stall less attractive and less useful for the cow. Clean stalls and clean cows are clearly desirable to reduce the risk of environmental mastitis (Schreiner and Ruegg, 2003; Zdanowicz et al., 2004), but reducing cow comfort seems to be a poor way of achieving this goal. We urge future designers of cow housing to consider options that meet the practical needs of dairy producers without reducing the comfort of the cows.

In summary, cows prefer to lie in stalls without a brisket board, and they spend less time lying down when forced to use stalls that contain this structure. These results indicate that the presence of a brisket board makes stalls less comfortable for cows.

\section{ACKNOWLEDGMENTS}

We thank Madelaine Hill for her help conducting this experiment and David Fraser for his comments on a previous draft of this manuscript. We also thank members of the UBC South Campus Research and Teaching Complex, the staff of the UBC Dairy Research and Education Centre, and the staff and students of the UBC Animal Welfare Program for their help and cooperation. This research was supported by the Natural Sciences and Engineering Research Council of Canada through the Industrial Research Chair in Animal Welfare, and by contributions from the Dairy Farmers of Canada, the British Columbia Dairy Foundation, the British Columbia Society for the Prevention of Cruelty to Animals, the British Columbia Veterinary Medical Association, and many other donors listed on our web site at http://www.landfood.ubc.ca/animalwelfare.

\section{REFERENCES}

Bergsten, C., and B. Pettersson. 1992. The cleanliness of cows tied in stalls and the health of their hooves as influenced by the use of electric trainers. Prev. Vet. Med. 13:229-238.

Conover, W. J., and R. L. Iman. 1981. Rank transformations as a bridge between parametric and nonparametric statistics. Am. Stat. 35:124-129.

Drissler, M., M. Gaworski, C. B. Tucker, and D. M. Weary. 2005. Freestall maintenance: Effects on lying behavior of dairy cattle. J. Dairy Sci. 88:2381-2387.

Fisher, A. D., M. Stewart, G. A. Verkerk, C. J. Morrow, and L. R. Matthews. 2003. The effects of surface type on lying behaviour and stress responses of dairy cows during periodic weather-induced removal from pasture. Appl. Anim. Behav. Sci. 81:1-11.

Gaworski, M., C. B. Tucker, D. M. Weary, and M. L. Swift. 2003. Effects of stall design on dairy cattle behaviour. Pages 139-146 in Fifth International Dairy Housing Conference. K. Janni, ed. American Society of Agricultural Engineers, Fort Worth, TX.

Haley, D. B., A. M. de Passillé, and J. Rushen. 2001. Assessing cow comfort: Effects of two floor types and two tie stall designs on the behaviour of lactating dairy cows. Appl. Anim. Behav. Sci. 71:105-117.

Haley, D. B., J. Rushen, and A. M. de Passillé. 2000. Behavioural indicators of cow comfort: Activity and resting behaviour of dairy cows in two types of housing. Can. J. Anim. Sci. 80:257-263.

Lowe, D. E., R. W. J. Steen, and V. E. Beattie. 2001. Preferences of housed finishing beef cattle for different floor types. Anim. Welf. 10:395-404.

Manninen, E., A. M. de Passillé, J. Rushen, M. Norring, and H. Saloniemi. 2002. Preferences of dairy cows kept in unheated buildings for different kind of cubicle flooring. Appl. Anim. Behav. Sci. 75:281-292.

Munksgaard, L., K. L. Ingvartsen, L. J. Pedersen, and V. K. M. Nielsen. 1999. Deprivation of lying down affects behaviour and pituitary-adrenal axis responses in young bulls. Acta Agric. Scand. A Anim. Sci. 49:172-178.

SAS Institute. 1999. User's Guide: Statistics, Version 8 ed. SAS Institute, Cary, NC.

Schreiner, D. A., and P. L. Ruegg. 2003. Relationship between udder and leg hygiene scores and subclinical mastitis. J. Dairy Sci. 86:3460-3465.

Stefanowska, J., D. Swierstra, J. V. van den Berg, and J. H. M. Metz. 2002. Do cows prefer a barn compartment with a grooved or slatted floor? J. Dairy Sci. 85:79-88.

Tucker, C. B., and D. M. Weary. 2004. Bedding on geotextile mattresses: How much is needed to improve cow comfort? J. Dairy Sci. 87:2889-2895.

Tucker, C. B., D. M. Weary, and D. Fraser. 2003. Effects of three types of free-stall surfaces on preferences and stall usage by dairy cows. J. Dairy Sci. 86:521-529.

Tucker, C. B., D. M. Weary, and D. Fraser. 2004. Free-stall dimensions: Effects on preference and stall usage. J. Dairy Sci. 87:1208-1216.

Tucker, C. B., D. M. Weary, and D. Fraser. 2005. Influence of neckrail placement on free-stall preference, use, and cleanliness. J. Dairy Sci. 88:2730-2737.

Veissier, I., J. Capdeville, and E. Delval. 2004. Cubicle housing systems for cattle: Comfort of dairy cows depends on cubicle adjustment. J. Anim. Sci. 82:3321-3337.

Zdanowicz, M., J. A. Shelford, C. B. Tucker, D. M. Weary, and M. A. G. von Keyserlingk. 2004. Bacterial populations on teat ends of dairy cows housed in free stalls and bedded with either sand or sawdust. J. Dairy Sci. 87:1694-1701. 